\title{
A Clinical Study of Relationship of Body Mass Index with Allergic Rhinitis
}

\author{
${ }^{1}$ Himanshu Kala, ${ }^{2}$ Sanjeev Bhagat, ${ }^{3}$ Saurabh Varshney, ${ }^{4}$ SS Bist
}

\section{ABSTRACT}

Objectives: Although the association between obesity and bronchial asthma (BA) has been gaining more attention, few studies have been conducted concerning the relationship between body mass index (BMI) and other allergic diseases. The purpose of this study is to determine the relationship between allergic rhinitis (AR) and BMI.

Materials and methods: This was a retrospective study. Two hundred and ten patients of AR (138 males and 72 females) and 424 healthy controls were included in the study. The BMI of patients and controls were calculated and correlated.

Results: The percentage of AR patients with a low BMI was $9.5 \%$, whereas $57.6 \%$ had a normal BMI; $21 \%$ were preobese and $9.5 \%$ were obese. In the control group, $48.6 \%$ subjects had normal BMI range followed by preobese $21.2 \%$, underweight $20.3 \%$, and obese $9.9 \%$. Among the overweight (preobese + obese) category, the maximum number of subjects belonged to cases, i.e., $32.8 \%$ with an odds ratio (OR) of 0.95 (95\% confidence interval $(\mathrm{Cl}) 0.91-1.07)$. Thus, AR was not associated with high BMI. Among the underweight, the maximum number of subjects belonged to the control group, i.e., $20.3 \%$ with an OR of $2.13(95 \% \mathrm{Cl} 1.24-3.68)$. Thus, AR had no relationship with lower BMI also. It was also observed that more of the female patients $(18,29.1$, and $12.5 \%$ were underweight, preobese, and obese respectively) had deranged BMI than male patients $(5.3,20.2$, and $7.9 \%$ were underweight, preobese, and obese respectively). A relative risk of 1.124 $(95 \% \mathrm{Cl} 1.01-1.23)$ and 1.04 (95\% Cl 0.95-1.13) was present in female patients with low and high BMI respectively, which is statistically significant $(p=0.0008)$.

Conclusion: It was concluded that BMI was not associated with increased prevalence of AR. Among the underweight and overweight, AR was more common in females than in males. Thus, BMI had a significant association with AR among female patients. Overall, BMI had no significant association with AR.

Keywords: Allergic rhinitis, Body mass index, Obesity.

How to cite this article: Kala H, Bhagat S, Varshney S, Bist SS. A Clinical Study of Relationship of Body Mass Index with Allergic Rhinitis. Clin Rhinol An Int J 2016;9(1):33-36.

Source of support: Nil

Conflict of interest: None

\footnotetext{
${ }^{1}$ Junior Resident, ${ }^{2}$ Associate Professor, ${ }^{3}$ Professor and Head ${ }^{4}$ Professor

${ }^{1-4}$ Department of ENT, Himalayan Institute of Medical Sciences Dehradun, Uttarakhand, India

Corresponding Author: Sanjeev Bhagat, Associate Professor Department of ENT, Government Medical College and Rajindra Hospital, Patiala, Punjab, India, Phone: +918283886628 e-mail: sbent224@gmail.com
}

\section{INTRODUCTION}

Allergic rhinitis (AR) is a global health problem involving nearly 600 million people all over the world. Its prevalence is closely related with age, gender, and lifestyle. The worldwide incidence of allergic symptoms and atopic reactions has gradually increased. ${ }^{1}$

Increased body mass index (BMI) and respiratory allergic diseases, such as asthma and AR, may be related. ${ }^{2-4}$ It would be interesting to see whether an association with obesity can be observed in allergic disease other than bronchial asthma (BA), such as AR. To date, few studies have investigated this issue. Von Mutius et $\mathrm{al}^{5}$ analyzed 7,370 children aged 4 to 17 years and found that the prevalence of BA, but not of allergy, was significantly associated with BMI. Bråbäck et $\mathrm{al}^{4}$ studied 1,247,038 Swedish adults over 3 decades and found an association between BMI and BA, but not with AR. Meanwhile, several investigations have shown a positive association between BMI and atopy, AR or AC, especially among female young adults and children..$^{6-8}$ Only few studies have reported positive associations between increased BMI and AR. ${ }^{9-11}$ Nevertheless, the mechanism for the association between respiratory allergic diseases and obesity and the reasons for the apparent difference between men and women remain unclear. ${ }^{2}$ Because both respiratory allergic diseases and obesity are characterized by inflammation, a common inflammatory pathway has been proposed as a plausible explanation for the association between respiratory allergy and obesity. ${ }^{12}$

Therefore, the aim of the present study was to investigate a possible relationship between BMI and AR.

\section{MATERIALS AND METHODS}

\section{Study Population}

This study was conducted at the Department of ENT, Himalayan Institute of Medical Sciences, Swami Ram Nagar, Dehradun, Uttarakhand, India, over a period of 12 months from July 31, 2010, to August 1, 2011. A total of 210 patients (6-80 years) with AR, including 138 (65.7\%) males and $72(34.3 \%)$ females and 424 healthy controls [241 (56.8\%) males and $183(43.2 \%)$ females], were included in the study.

Four BMI categories were created according to WHO criteria: 30.00 and above (obese), 25.00-29.99 (preobese), 
Table 1: Distribution of allergic rhinitis cases according to body mass index and gender

\begin{tabular}{llllll}
\hline & \multicolumn{5}{c}{ Body mass index $\left(\mathrm{kg} / \mathrm{m}^{2}\right)$} \\
\cline { 2 - 6 } & No. of patients & Underweight & Normal range & Preobese & Obese \\
\hline In males & $138(65.7 \%)$ & $07(05.0 \%)$ & $92(69.6 \%)$ & $28(20.2 \%)$ & $11(07.9 \%)$ \\
In females & $72(34.3 \%)$ & $13(18.0 \%)$ & $29(40.2 \%)$ & $21(29.1 \%)$ & $09(12.5 \%)$ \\
\hline Total & $210(100 \%)$ & $20(09.5 \%)$ & $121(57.6 \%)$ & $49(23.3 \%)$ & $20(09.5 \%)$ \\
\hline
\end{tabular}

18.50-24.99 (normal range), and 18.49 and lower (underweight). ${ }^{13}$

The odds ratios (ORs) with 95\% confidence intervals (CIs) for diagnosed AR were calculated for four successive BMI categories. Allergic rhinitis was diagnosed on the basis of history and examination. All patients underwent nasal endoscopy to document nasal inflammation and/ or nasal polyposis. Relevant hematological (absolute eosinophil count and serum immunoglobulin E) and radiological investigation (X-ray paranasal sinuses water's view) were undertaken. Exclusion criteria included non-AR and patients with reduced BMI with other debilitating diseases.

\section{Statistical Analysis}

The statistical analysis was done using the Statistical Package for the Social Sciences (SPSS) Version 16.0 statistical analysis software. Relative risk and OR were used to find different correlations.

\section{RESULTS}

We analyzed 210 patients of AR and compared their BMI with 424 controls. In this study, no patient showed any significant abnormal systemic finding.

\section{Relative Risk for Allergic Rhinitis Cases in Four BMI Categories between Men and Women}

It was observed that in the underweight category, AR cases were more common in females (18.0\%) than males
Table 2: Relative risk for allergic rhinitis cases in four body mass index categories between men and women

\begin{tabular}{lll}
\hline & Relative risk & Confidence interval \\
\hline Underweight & 1.124 & $1.01-1.23$ \\
Normal range & 0.841 & $0.71-0.99$ \\
Preobese & 1.074 & $0.94-1.22$ \\
Obese & 1.042 & $0.95-1.13$ \\
\hline
\end{tabular}

(05.3\%) with relative risk (RR) of 1.124 (95\% CI 1.01-1.23) (Table 1). High BMI in AR cases was observed more commonly in females than males. It was seen that $29.1 \%$ female and $20.2 \%$ male patients were preobese, with RR 1.074 (95\% CI $0.94-1.22$ ), whereas $12.5 \%$ of females and $7.9 \%$ of male patients were obese, with RR 1.04 (95\% CI 0.95-1.13). The p-value was also found to be statistically significant (0.0008) (Table 2).

\section{Association of BMI with Allergic Rhinitis among Cases and Controls}

The maximum number of patients had normal BMI $(57.6 \%)$, followed by preobese $(21 \%) ; 9.5 \%$ cases were obese and 9.5\% were underweight (Tables 3 and 4 ).

In the underweight category, the maximum number of subjects belonged to the control group, i.e., $20.3 \%$ with an OR of 2.13 (95\% CI 1.24-3.68). It is thus clear that BMI had no relationship with AR in the underweight category.

Among the overweight (preobese + obese), the maximum number of subjects belonged to cases, i.e., $32.8 \%$ with an OR of 0.95 (95\% CI 0.91-1.07); thus, BMI had no relationship with OR in this category.

Table 3: Comparing body mass index with cases and controls

\begin{tabular}{|c|c|c|c|c|}
\hline Body mass index $\left(\mathrm{kg} / \mathrm{m}^{2}\right)$ & Cases & & Controls & \\
\hline Underweight & $20(09.5 \%)$ & & $86(20.3 \%)$ & \\
\hline Normal range & $121(57.6 \%)$ & & $206(48.6 \%)$ & \\
\hline Preobese & $49(23.3 \%)$ & \multirow{2}{*}{$\begin{array}{l}\text { Overweight (i.e., preobese + } \\
\text { obese })=69(32.8 \%)\end{array}$} & $90(21.2 \%)$ & \multirow{2}{*}{$\begin{array}{l}\text { Overweight (i.e., preobese+ } \\
\text { obese) }=132(30.1 \%)\end{array}$} \\
\hline Obese & $20(09.5 \%)$ & & $42(09.9 \%)$ & \\
\hline Total & $210(100 \%)$ & & $424(100 \%)$ & \\
\hline
\end{tabular}

Table 4: Odds ratio for allergic rhinitis in four body mass index categories between cases and controls

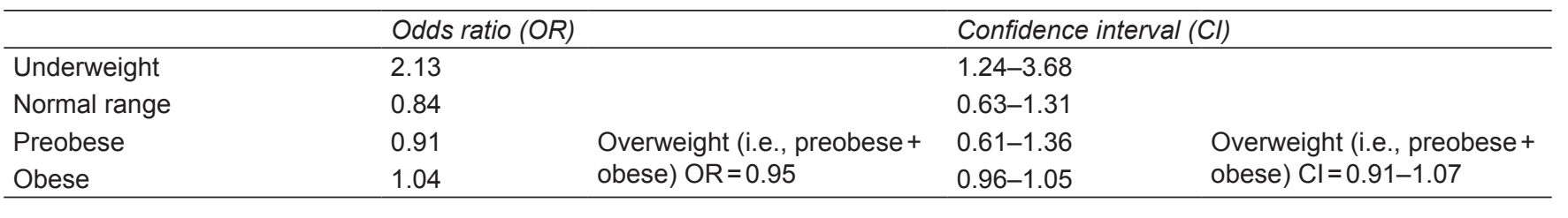




\section{DISCUSSION}

There is evidence that the prevalence of allergic disorders, such as rhinitis and asthma, has increased worldwide in developed countries. ${ }^{14}$ The real association between obesity and allergic disorders is unclear. Many crosssectional surveys have pointed out that obesity is a risk factor for AR. 6,9-11 Moreover, a gender-dependent influence was observed and a significant association between body fat and AR in women but not in men was found. - $^{6}$

In our study, we observed that increased BMI was associated with higher prevalence of AR in females but not in males. Also, in the underweight category, AR cases were more common in females than males. Kilpelainen et al conducted a study to find an association between BMI and physician-diagnosed allergic rhinoconjunctivitis. This study included 10,667 students aged 18 to 25 years and concluded that the risk of allergic rhinoconjunctivitis increased with BMI among women but not men. ${ }^{6}$ Similarly, Schachter et $\mathrm{al}^{7}$ in their study of overweight Australian children (age 7-12 years) reported that higher value of BMI was significantly associated with higher prevalence of atopy only in girls. Huang et $\mathrm{al}^{8}$ reported in a cross-sectional survey among 1,459 students (age 13.2-15.5; mean 13.6 years) in northern Taiwan that BMI was a significant predictor of atopy, allergic symptoms and in teenage girls. Only one study by Ciprandi et $\mathrm{al}^{9}$ reported a significant association between increased BMI and AR in males. This finding is conflicting with previous studies and with our study ${ }^{6-8}$ In fact, this study failed to find any association between AR and BMI in women because of the low number of females.

Considering the gender, a different association could be related to the difference in hormonal levels, inflammatory markers, or body fat distribution. Overweight condition may lead to unwanted variations in immunological balance. We have no explanation for the slightly increased risk of AR in the female underweight category.

The studies reporting the association between obesity and atopic disease or sensitization have given conflicting results. The risk of sensitization was equal in all BMI quartiles in children in the United States ${ }^{5}$ and among adults taking part in the European Community Respiratory Health Survey (ECRHS). ${ }^{15}$ The study, conducted on a large cohort of Swedish military conscripts, reported that obesity was not associated with AR in patients with nasal symptoms only. ${ }^{4}$ A similar observation was reported by Jarvis et al, who conducted a study to find an association between BMI and atopy and concluded that BMI was not associated with "hay fever or nasal allergies," in both men and women. ${ }^{15}$ Consistent with these reports, in our study also no association was seen between BMI values and AR.
Contrary to the above-mentioned studies, Paksoy et al reported that there was a strong relationship between BMI values and AR. They analyzed 651 students in order to identify the effect of AR on the growth levels and BMI in children. ${ }^{10}$ Ciprandi et $a l^{9}$ in their study of 100 patients with moderate to severe persistent AR found that BMI values were significantly lower in control subjects (mean 24.0) with respect to patients with rhinitis (mean 25.5). Another study by Ciprandi et al, ${ }^{11}$ which included 155 patients with persistent AR alone and 155 healthy controls, established that BMI values were significantly higher in AR patients than in control subjects $(p=0.038)$. Differences in age range and the reliability of questionnaire-based diagnoses might be responsible for the reported controversial results on nasal allergies. In the present study, physician-diagnosed AR was shown to be highly specific.

However, this study may have some limitations: It has been conducted on a restricted and selected cohort of patients, mainly concerning gender and age; BMI may be a simplistic tool for measuring overweight/obesity; and the methodology was principally based on clinical grounds and was cross-sectional.

\section{CONCLUSION}

In our study, AR per se had no relationship with overweight or obesity. But association between increasing BMI and AR was found in women. It would be interesting to find out whether the association could be explained by the interplay of leptin and estrogen hormone on allergic inflammation. The association between BMI and AR could be more diverse, and in order to find a good correlation between $\mathrm{BMI}$ and $\mathrm{AR}$, we have to match the confounding factors affecting BMI. Further studies should be done in order to understand the complex etiology of the diseases that may lead to new management for AR.

\section{REFERENCES}

1. Mullol J, Valero L, Alobid I, Bartra J, Navarro AM, Chivato T, Khaltaev N, Bousquet J. Allergic rhinitis and its impact on asthma update (ARIA 2008). The perspective from Spain. J Investig Allergol Clin Immunol 2008;18(5):327-334.

2. McLachlan CR, Poulton R, Car G, Cowan J, Filsell S, Greene JM, Taylor DR, Welch D, Williamson A, Sears MR, et al. Adiposity, asthma, and airway inflammation. J Allergy Clin Immunol 2007 Mar;119(3):634-639.

3. Ford ES. The epidemiology of obesity and asthma. J Allergy Clin Immunol 2005 May;115(5):897-909.

4. Bråbäck L, Hjern A, Rasmussen F. Body mass index, asthma and allergic rhinoconjunctivitis in Swedish conscripts - A national cohort study over 3 decades. Respir Med 2005 Aug;99(8):1010-1014.

5. Von Mutius E, Schwartz J, Meas LM, Dockery D, Weiss ST. Relation of body mass index to asthma and atopy in children: 
The national health and nutrition examination study III. Thorax 2001 Nov;56(11):835-358.

6. Kilpelainen M, Eerho EO, Helenius H, Koskenvuo M. Body mass index and physical activity in relation to asthma and atopic diseases in young adults. Respir Med 2006 Sep;100(9): 1518-1525.

7. Schachter LM, Peat JK, Salome CM. Asthma and atopy in overweight children. Thorax 2003 Dec;58(12):1031-1035.

8. Huang SL, Shiao G, Chou P. Association between body mass index and allergy in teenage girls in Taiwan. Clin Exp Allerg 1999 Mar;29(3):323-329.

9. Ciprandi G, Pistorio A, Tosca M, Ferraro MR, Cirillo I. Body mass index, respiratory function and bronchial hyperreactivity in allergic rhinitis and asthma. Respir Med 2009 Feb 24;103(2):289-295.

10. Paksoy M, Eken M, Aydin S, Oktay AZ, Hardal U, Salini A, Zeren NY. The effect of allergic rhinitis on growth, development and body mass indices in school children. Indian J Otolaryngol Head Neck Surg 2010 Jan;62(1):64-68.

11. Ciprandi G, Ricciardolo FLM, Signori A, Schiavetti I, Monardo M, Ferraro MR, Cirillo I. Increased body mass index and bronchial impairment in allergic rhinitis. Am J Rhinol Allergy 2013 Nov-Dec;27(6):e195-e201.

12. Weiss S. Obesity: Insight into the origins of asthma. Nat Immunol 2005 Jun;6(6):537-539.

13. WHO. Obesity. Preventing and managing the global epidemic. Report of a WHO consultation on obesity. Geneva: World Health Organization; 1998.

14. Asher I. ISAAC International Study of Asthma and Allergies in Childhood. Pediatr Pulmonol 2007 Jan;42(1):100.

15. Jarvis D, Chinn S, Potts J, Burney P. Association of body mass index with respiratory and atopy: results from European Community Respiratory Health Survey. Clin Exp Allergy 2002 Jun;32(6):831-837. 